ARTICLE

\title{
High-specific-power flexible transition metal dichalcogenide solar cells
}

\author{
Koosha Nassiri Nazif (10) 1,8, Alwin Daus ${ }^{1,8}$, Jiho Hong (1) 2,3, Nayeun Lee 2,3, Sam Vaziri ${ }^{1}$, Aravindh Kumar (1) 1,

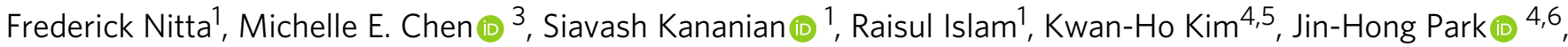 \\ Ada S. Y. Poon (10 1, Mark L. Brongersma (i) 2,3,7, Eric Pop (iD) ${ }^{1,3}$ \& Krishna C. Saraswat (i) ${ }^{1,3 凶}$
}

\begin{abstract}
Semiconducting transition metal dichalcogenides (TMDs) are promising for flexible highspecific-power photovoltaics due to their ultrahigh optical absorption coefficients, desirable band gaps and self-passivated surfaces. However, challenges such as Fermi-level pinning at the metal contact-TMD interface and the inapplicability of traditional doping schemes have prevented most TMD solar cells from exceeding $2 \%$ power conversion efficiency (PCE). In addition, fabrication on flexible substrates tends to contaminate or damage TMD interfaces, further reducing performance. Here, we address these fundamental issues by employing: (1) transparent graphene contacts to mitigate Fermi-level pinning, (2) $\mathrm{MoO}_{x}$ capping for doping, passivation and anti-reflection, and (3) a clean, non-damaging direct transfer method to realize devices on lightweight flexible polyimide substrates. These lead to record PCE of 5.1\% and record specific power of $4.4 \mathrm{~W} \mathrm{~g}^{-1}$ for flexible TMD $\left(\mathrm{WSe}_{2}\right)$ solar cells, the latter on par with prevailing thin-film solar technologies cadmium telluride, copper indium gallium selenide, amorphous silicon and III-Vs. We further project that TMD solar cells could achieve specific power up to $46 \mathrm{~W} \mathrm{~g}^{-1}$, creating unprecedented opportunities in a broad range of industries from aerospace to wearable and implantable electronics.
\end{abstract}

\footnotetext{
${ }^{1}$ Department of Electrical Engineering, Stanford University, Stanford, CA 94305, USA. ${ }^{2}$ Geballe Laboratory for Advanced Materials, Stanford University, Stanford, CA 94305, USA. ${ }^{3}$ Department of Materials Science and Engineering, Stanford University, Stanford, CA 94305, USA. ${ }^{4}$ Department of Electrical and Computer Engineering, Sungkyunkwan University, Suwon 16419, Korea. ${ }^{5}$ Department of Electrical and Systems Engineering, University of Pennsylvania, Philadelphia, PA 19104, USA. ${ }^{6}$ SKKU Advanced Institute of Nanotechnology (SAINT), Sungkyunkwan University, Suwon 16419, Korea. ${ }^{7}$ Department of Applied Physics, Stanford University, Stanford, CA 94305, USA. ${ }^{8}$ These authors contributed equally: Koosha Nassiri Nazif, Alwin Daus.

凶email: saraswat@stanford.edu
} 
C onventional silicon ( $\mathrm{Si}$ ) solar cells dominate the photovoltaics market with a market share of about $95 \%$ due to their low-cost manufacturing and reasonable power conversion efficiency (PCE) ${ }^{1}$. However, the low optical absorption coefficient and brittle nature of Si lead to degraded performance in ultrathin, flexible $\mathrm{Si}$ solar cells and therefore prevent their broader usage in applications demanding high power per weight (i.e., specific power, $P_{\mathrm{S}}$ ) and flexibility, for example in aerospace, transportation, architecture, and self-powered wearable and implantable electronics ${ }^{2-10}$.

Emerging semiconducting transition metal dichalcogenides (TMDs) exhibit excellent properties for such flexible highspecific-power photovoltaics. These include ultrahigh optical absorption coefficients up to one order of magnitude greater than conventional direct bandgap semiconductors, near-ideal band gaps for solar energy harvesting, and self-passivated surfaces ${ }^{11-18}$. In fact, ultrathin $(<20 \mathrm{~nm})$ TMDs can achieve near-unity, broadband, and omnidirectional absorption in the visible spectrum $^{15,16}$. The wide range of TMD band gaps $(\sim 1.0-2.5 \mathrm{eV})^{17}$ are also well suited for highly efficient single-junction or doublejunction tandem solar cells ${ }^{13}$. In addition, the dangling-bond-free surfaces of layered TMDs enable heterostructures without the constraint of lattice matching, offering abundant design choices for TMD photovoltaics ${ }^{18}$. According to realistic detailed balance models ${ }^{13}$, a PCE of $\sim 27 \%$ can be achieved in ultrathin singlejunction TMD solar cells, leading to extremely high $P_{\mathrm{S}}$ once implemented on lightweight flexible substrates ${ }^{8}$.

Despite these promising forecasts, there have not been any such demonstrations due to difficulties in reaching high PCE and integrating materials on flexible substrates. The PCE of TMD solar cells has typically not exceeded $2 \%^{19-25}$, mostly due to strong Fermi-level pinning at the metal contact-TMD interface ${ }^{26}$ and the inapplicability of traditional doping schemes such as diffusion or ion implantation, which can damage TMDs ${ }^{27}$. Reducing or eliminating Fermi-level pinning by adopting a gentle metal transfer method ${ }^{22,26}$, introducing an ultrathin interlayer at the metal-TMD interface ${ }^{28-31}$, or forming a van der Waals $(\mathrm{vdW})$ heterojunction such as graphene-TMD ${ }^{32-34}$ can significantly improve the performance of TMD devices. In addition, forming a $\mathrm{p}-\mathrm{n}$ homojunction by employing TMD-compatible doping methods such as surface charge transfer and fixed charge doping via metal oxides ${ }^{23-25}$, plasma doping ${ }^{35}$, or electrostatic doping ${ }^{36}$ has been shown to enhance the photovoltaic performance. Noteworthily, the highest PCEs in thin-film singlejunction TMDs are 2.8\% in plasma-doped $\mathrm{MoS}_{2}$ and $6.3 \%$ in electrostatically-doped $\mathrm{MoSe}_{2}$ solar cells ${ }^{35,36}$. At the same time, TMDs are typically transferred to flexible substrates and most of these processes can damage TMD interfaces, leave unwanted polymer residues, and do not allow for a reliable and practical vertical device architecture ${ }^{37}$. Previous reports on $P_{\mathrm{S}}$ of TMD solar cells, i.e., $3 \mathrm{~W} \mathrm{~g}^{-1}$ with a PCE of $0.46 \%{ }^{22}$ and $2500 \mathrm{~W} \mathrm{~g}^{-1}$ with a PCE of $1.0 \%{ }^{14}$, do not account for the substrate's weight, which practically constitutes the largest part of the overall weight and needs to be considered for accurate $P_{\mathrm{S}}$ calculations. The only TMD solar cell on a lightweight, flexible substrate reported to date has a PCE of $<0.7 \%$, yielding a $P_{\mathrm{S}}$ of $<0.04 \mathrm{~W} \mathrm{~g}^{-120}$.

Here, we address the above-mentioned device and integration challenges by utilizing transparent graphene contacts mitigating Fermi-level pinning, $\mathrm{MoO}_{x}$ capping for doping, passivation and anti-reflection coating, and a clean, non-damaging direct transfer method to realize TMD solar cells for the first time on an ultrathin $(5 \mu \mathrm{m})$, lightweight and flexible polyimide (PI) substrate. The flexible TMD ( $\left.\mathrm{WSe}_{2}\right)$ solar cells made in this fashion achieve a PCE of 5.1\%, surpassing previous flexible TMD solar cells by more than an order of magnitude ${ }^{20}$. Furthermore, the integration on an ultrathin substrate enables a $P_{\mathrm{S}}$ of $4.4 \mathrm{~W} \mathrm{~g}^{-1}$, more than $100 \times$ higher than previous results on flexible TMD photovoltaics $^{20}$ and in the same range as champion solar cells of prevailing thin-film technologies cadmium telluride (CdTe), copper indium gallium selenide (CIGS), amorphous silicon (a-Si) and group III-V semiconductors ${ }^{38-45}$. In future, TMD solar cells on even thinner substrates and with higher PCEs could potentially achieve an unprecedented $P_{\mathrm{S}}$ of $\sim 46 \mathrm{~W} \mathrm{~g}^{-1}$ (as we project in this work) opening up far-reaching possibilities in a broad range of industries ${ }^{9}$.

\section{Results and discussion}

Design and fabrication of flexible $\mathrm{WSe}_{2}$ solar cells. We fabricate flexible vertical photovoltaic cells from multilayer $(\sim 200 \mathrm{~nm})$ tungsten diselenide ( $\mathrm{WSe}_{2}$ ) absorbers, transparent hole-collecting graphene top contacts covered by $\mathrm{MoO}_{x}$ doping, passivation and anti-reflection coatings, and optically-reflective electron-collecting gold $\mathrm{Au}$ ) bottom contacts. The bottom contact and absorber material are embedded into a flexible, transparent polyimide substrate. Device schematics and optical images are shown in Fig. 1a-d. We mechanically exfoliate $\mathrm{WSe}_{2}$ flakes on thermally oxidized silicon substrates and deposit patterned $\mathrm{Au}$ bottom contacts, which are all covered with spin-coated polyimide and released together in deionized water ${ }^{46}$. The patterned transparent top contacts constituted of graphene and $\mathrm{MoO}_{x}$ are then formed on top via graphene wet transfer and $\mathrm{MoO}_{x}$ electron-beam (ebeam) evaporation. Details on device fabrication and transfer procedures can be found in Supplementary Note 1 and Supplementary Fig. 1.

Figure 1e shows the schematic energy band diagram of flexible $\mathrm{WSe}_{2}$ solar cells based on energy levels of $\mathrm{WSe}_{2}$, graphene $(\mathrm{Gr})$, and $\mathrm{Au}$ reported in the literature. $\mathrm{WSe}_{2}$ has a bulk band gap of $\sim 1.2 \mathrm{eV}$ and electron affinity of $\sim 4.0 \mathrm{eV}^{21,47-49}$, and is undoped according to the bulk crystal vendor. Due to the energetic nature of e-beam evaporation, defect states are induced at the $\mathrm{Au}-\mathrm{WSe}_{2}$ interface, and the Au Fermi level is pinned toward the charge neutrality level of $\mathrm{WSe}_{2}$ located around midgap ${ }^{26,50,51}$. This decreases the effective work function of $\mathrm{Au}$ and makes it a decent electron-collecting contact. We find that replacing Au with lower work function metals such as $\mathrm{Ti}$ and $\mathrm{Al}$ leads to a lower performance, most probably due to their reactive nature therefore forming poor interfaces with $\mathrm{WSe}_{2}$ (Supplementary Fig. 2) ${ }^{52}$. On the other hand, layered materials $\mathrm{Gr}$ and $\mathrm{WSe}_{2}$ experience no Fermi-level pinning at their vdW interface ${ }^{32-34}$. The work function of undoped graphene is $\sim 4.6 \mathrm{eV}$ (e.g., in vacuum), which increases to $\sim 5.0 \mathrm{eV}$ when graphene is exposed to air ${ }^{53-55}$. Graphene and the undoped $\mathrm{WSe}_{2}$, therefore, form a Schottky junction with a hole barrier height of $0.1-0.2 \mathrm{eV}$ and a built-in potential of $0.4-0.5 \mathrm{eV}^{33,34,56}$. The $\mathrm{MoO}_{x}$ on top further p-dopes graphene, increasing its work function and therefore the built-in potential of the Gr-WSe ${ }_{2}$ Schottky junction by $\sim 0.16 \mathrm{eV}$ (Supplementary Note 2, Supplementary Table 1 and Supplementary Fig. 3a, b). $\mathrm{MoO}_{x}$ also passivates the top surface of the solar cell, specifically the trap states at the $\mathrm{Gr}-\mathrm{WS} \mathrm{S}_{2}$ interface ${ }^{24}$. These lead to a higher open-circuit voltage $\left(V_{\mathrm{OC}}\right)$ and short-circuit current density $\left(J_{\mathrm{SC}}\right)$ in $\mathrm{MoO}_{x}$-capped $\mathrm{WSe}_{2}$ solar cells (Supplementary Note 2 and Supplementary Fig. 3c). As we will discuss later in the optical characterization section, $\mathrm{MoO}_{x}$ also serves as an effective anti-reflection coating for $\mathrm{WSe}_{2}$, leading to an additional increase in $J_{\mathrm{SC}}$. Given the approximate locations of $\mathrm{Gr}$, $\mathrm{WSe}_{2}$, and Au Fermi levels, the depletion regions of $\mathrm{Gr}-\mathrm{WSe}_{2}$ and $\mathrm{Au}-\mathrm{WSe}_{2}$ Schottky junctions are estimated to be in the order of 1 $\mu \mathrm{m}$ and therefore expand throughout the entire depth of the $\sim 200$-nm-thick $\mathrm{WSe}_{2}$ layer, leading to fully depleted devices with a built-in potential of $\sim 0.6 \mathrm{eV}$. 
a
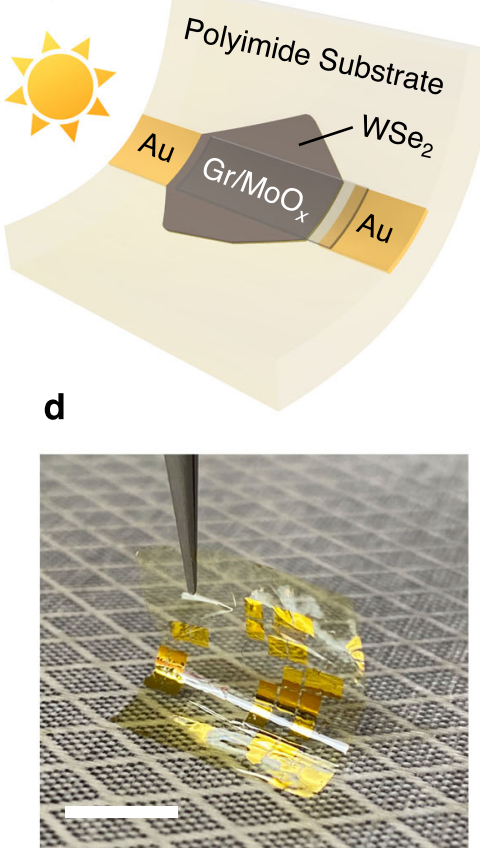

b

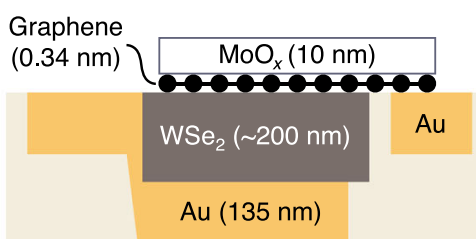

Flexible Polyimide Substrate $(\sim 5 \mu \mathrm{m})$

e

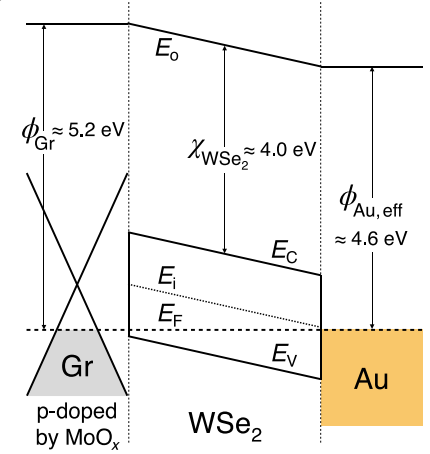

C

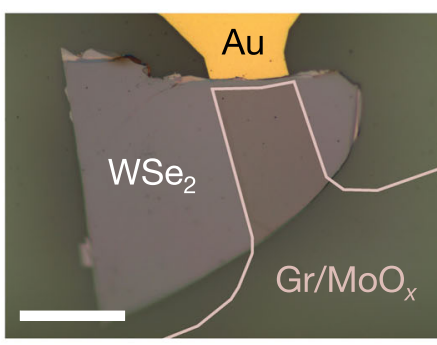

f

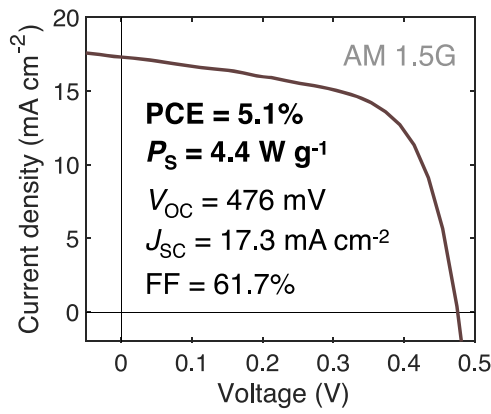

Fig. 1 Flexible $\mathbf{W S e} \mathbf{2}_{\mathbf{2}}$ solar cells. a Device schematic and $\mathbf{b}$ cross-section. c Top-down optical image of the device. Scale bar, $50 \mu \mathrm{m}$. $\mathbf{d}$ Photograph of WSe 2 solar cells on a flexible polyimide substrate. Scale bar, $1 \mathrm{~cm}$. e Qualitative energy band diagram of the device. The Fermi level ( $E_{\mathrm{F}}$ ) is pinned near the midgap at the $\mathrm{Au}_{-} \mathrm{WSe}_{2}$ interface, but not at the van der Waals graphene (Gr)-WSe ${ }_{2}$ interface 26,32,33,50,51. MoO ${ }_{x}$ increases the Gr work function and the built-in potential of the Gr-WSe 2 Schottky junction ${ }^{53}$. $E_{0}$, vacuum level; $E_{C}$, conduction band edge; $E_{V}$, valence band edge; $E_{\mathrm{i}}$, intrinsic Fermi level; $\Phi_{\mathrm{Au}}$, eff, Au

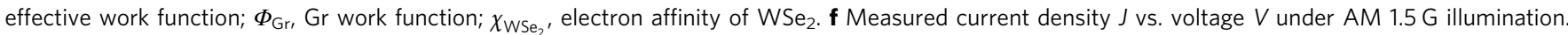
PCE, power conversion efficiency. $P_{\mathrm{S}}$ specific power or power per weight. $V_{\mathrm{OC}}$ open-circuit voltage. $J_{\mathrm{SC}}$ short-circuit current. FF fill factor.

Photovoltaic performance. Under global air mass AM $1.5 \mathrm{G}$ illumination, the flexible $\mathrm{WSe}_{2}$ solar cells achieve $V_{\mathrm{OC}}$ of $476 \mathrm{mV}$, a $J_{\mathrm{SC}}$ of $17.3 \mathrm{~mA} \mathrm{~cm}^{-2}$, and a fill factor (FF) of $61.7 \%$ (Fig. 1f), leading to an unprecedented PCE of $5.1 \%$ in flexible TMD solar cells, over $10 \times$ higher than previous demonstrations $(<0.7 \%)^{20}$. Having an ultrathin absorber layer and a lightweight polyimide substrate, these $\mathrm{WSe}_{2}$ solar cells also achieve a high-specific power $\left(P_{\mathrm{S}}\right)$ of $4.4 \mathrm{~W} \mathrm{~g} \mathrm{~g}^{-1}$ (calculated in Supplementary Note 3 using the data in Supplementary Table 2 ), over $100 \times$ higher than preceding results $\left(<0.04 \mathrm{~W} \mathrm{~g}^{-1}\right)^{20}$ and on par with champion solar cells from well-established thin-film technologies CdTe, CIGS, a-Si, and III-Vs ${ }^{38-45}$. The device has a shunt resistance of $226 \Omega \mathrm{cm}^{2}$ and a series resistance of $3.1 \Omega \mathrm{cm}^{2}$, calculated by inversing the slope of the $J-V$ curve at short-circuit and open-circuit conditions, respectively, yielding the reasonable FF of $61.7 \%$. We measure reproducible performance in all nine devices fabricated (Supplementary Fig. 4). No hysteresis is observed in the $J-V$ characteristics when sweeping the voltage in the forward and backward directions (Supplementary Fig. 5). Similar $J-V$ characteristics are observed in solar cells with undoped tungsten disulfide $\left(\mathrm{WS}_{2}\right)$ absorber layers. However, due to their lower built-in potential, $\mathrm{WS}_{2}$ solar cells exhibit lower $V_{\mathrm{OC}}, J_{\mathrm{SC}}, \mathrm{FF}$, and hence PCE (Supplementary Fig. 6).

Electrical characterization. Next, we measure the current density vs. voltage $(J-V)$ characteristics of flexible $\mathrm{WSe}_{2}$ solar cells in the dark and for AM 1.5 G illumination at various incident power intensities (Fig. 2a, b). As shown in Fig. 1e, Au is not an ohmic n-type contact and, similar to Gr, forms a Schottky junction with $\mathrm{WSe}_{2}$, resulting in a back-to-back diode structure (Fig. 2a, inset). This undesirable Schottky barrier at the Au back contact leads to the roll-over phenomenon where the slope of the $J-V$ curve is reduced at high forward biases ${ }^{57,58}$, starting here at around
$V=0.65 \mathrm{~V}$. The barrier also causes the cross-over of dark and light $J-V$ curves at $V=0.53 \mathrm{~V}$, which can be explained by the presence of a minority carrier surface recombination current at the $\mathrm{Au}-\mathrm{WSe}_{2}$ interface ${ }^{58}$. The two phenomena are also frequently observed in CdTe and CIGS solar cells ${ }^{57-59}$.

Figure $2 \mathrm{~b}$ shows a zoomed-in view of the photovoltaic region. An analysis of this data indicates that the shunt resistance decreases almost linearly with increasing incident intensity (Supplementary Fig. 7). This phenomenon, known as photoshunting, occurs due to increased minority carrier conductivity across the device under illumination ${ }^{60,61}$. Improving the charge carrier selectivity of the solar cell, for example by utilizing carrierselective metal-interlayer-semiconductor (MIS) contacts or introducing a high built-in potential $\mathrm{p}-\mathrm{n}$ homojunction could reduce or eliminate photoshunting. Given the initially high shunt resistance of the device, photoshunting does not affect the shape of the $J-V$ curve, and therefore fill factor stays constant at various intensities.

By fitting a power-law equation on the measured current density and incident power data (Fig. 2c), we observe that shortcircuit current density versus incident power follow a linear trend $\left(J_{\mathrm{SC}}=\beta \cdot\left(P_{\text {in }}\right)^{\alpha}, \alpha=1\right)$, expected from a well-designed solar cell. Equation 1 is a rearrangement of the diode equation in the presence of photogeneration $\left(J_{\text {photo }}=J_{\mathrm{SC}}\right)$ and shunt resistance $\left(R_{\mathrm{SH}}\right)$ at $V=V_{\mathrm{OC}}$, leading to zero current density by definition $(J=0)$. In this equation, $n$ is the diode ideality factor, $k_{\mathrm{B}}$ is the Boltzmann constant, $T$ is the absolute temperature, $q$ is the elementary charge, and $J_{\mathrm{o}}$ is the dark saturation current. According to this equation, $V_{\mathrm{OC}}$ scales linearly with $\ln \left(J_{\mathrm{SC}}-\right.$ $\left.V_{\mathrm{OC}} / R_{\mathrm{SH}}\right)$ when $\left(J_{\mathrm{SC}}-V_{\mathrm{OC}} / R_{\mathrm{SH}}\right) / J_{\mathrm{o}} \gg 1$, valid for the $\mathrm{WSe}_{2}$ solar cells in this study. By fitting the measured $V_{\mathrm{OC}}$ and $J_{\mathrm{SC}}-V_{\mathrm{OC}} / R_{\mathrm{SH}}$ (Fig. 2d), we extract $n$ and $J_{\mathrm{o}}$ of the $\mathrm{WSe}_{2}$ solar cells, neglecting the $\mathrm{Au}$ back Schottky diode for simplicity. 
a

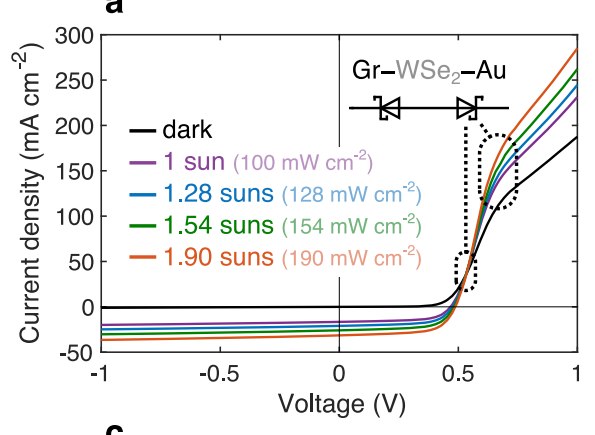

C

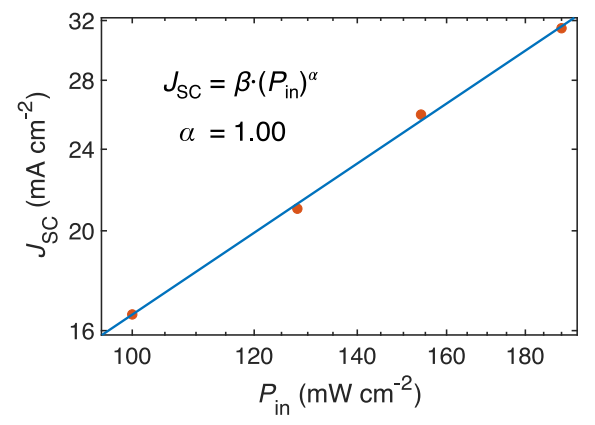

b

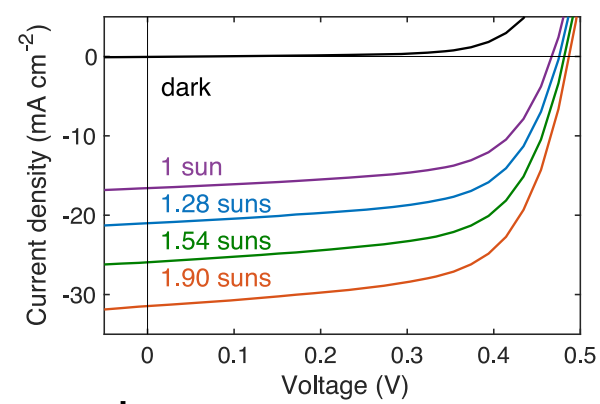

d

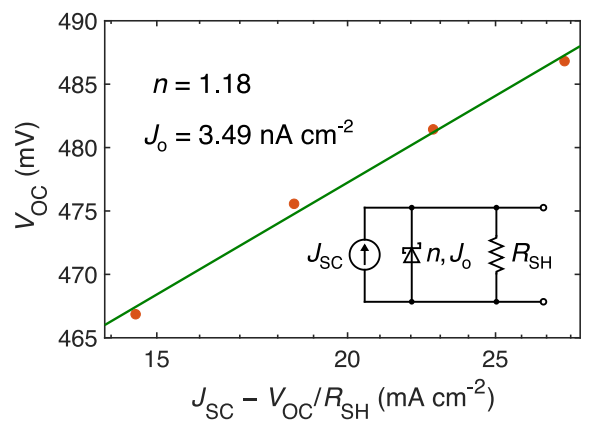

Fig. 2 Electrical characteristics of flexible WSe $\mathbf{2}_{\mathbf{2}}$ solar cells. a Current density vs. voltage $(J-V)$ characteristics of $\mathrm{WSe}_{2}$ solar cells under $\mathrm{AM} 1.5 \mathrm{G}$ illumination, at various incident power. Inset represents the circuit diagram of $\mathrm{Au}-\mathrm{WS} \mathrm{e}_{2}$ and $\mathrm{Gr}-\mathrm{WS} \mathrm{e}_{2}$ junctions. With its Fermi level pinned around midgap, Au forms a Schottky junction to WSe $\mathrm{W}_{2}$ opposing the main $\mathrm{Gr}-\mathrm{WSe}_{2}$ Schottky junction, leading to cross-over and roll-over effects occurring around 0.53 and $0.65 \mathrm{~V}$, respectively 57,58 , as marked by dotted ovals. b Zoomed-in view of the photovoltaic region of the J-V measurements shown in a. c Shortcircuit current density $\left(J_{S C}\right)$ of the devices. $P_{\text {in }}$ incident power; symbols, measurements; line, power law fit. d Open-circuit voltage $\left(V_{O C}\right)$ of the devices. Note logarithmic axes in $\mathbf{c}$ and horizontal axis in $\mathbf{d}$. $R_{\mathrm{SH}}$, shunt resistance; symbols, measurements; line, fit. Inset shows a representative circuit diagram. $n$ is the ideality factor and $J_{0}$ the dark saturation current density from the diode fit.

$\mathrm{WSe}_{2}$ solar cells demonstrate a desirable near-unity ideality factor of $n=1.18$ and dark saturation current of $J_{\mathrm{o}}=3.49 \mathrm{nA} \mathrm{cm}^{-2}$. The near-unity ideality factor and small dark saturation current indicate low levels of charge carrier recombination and therefore a high internal quantum efficiency as confirmed later by comparing the measured $J_{\mathrm{SC}}$ and $J_{\mathrm{SC}}$, max derived from absorption measurements.

$$
V_{\mathrm{OC}}=\frac{n k_{\mathrm{B}} T}{q} \ln \left(\frac{J_{\mathrm{SC}}-\frac{V_{\mathrm{OC}}}{R_{\mathrm{SH}}}}{J_{\mathrm{O}}}+1\right)
$$

Optical characterization and simulation. Figure 3 a shows the optical image, spatial light beam-induced current (LBIC or photocurrent) map acquired at a wavelength of $530 \mathrm{~nm}$, and their overlay for a typical flexible $\mathrm{WSe}_{2}$ solar cell. The overlay map shows that only the Gr-WSe $e_{2}$ diode is responsible for splitting photogenerated holes and electrons and therefore producing photocurrent. No photocurrent generation is observed at the $\mathrm{Au}-\mathrm{WSe}_{2}$ back diode. This can be seen at the narrow $\mathrm{WSe}_{2}$ region near the Au contact line on the left, where the Au bottom contact is present, but no Gr is covering the $\mathrm{WSe}_{2}$. In contrast, a strong photocurrent is measured on the opposite side of the $\mathrm{WSe}_{2}$ on the right, where the Au back contact is absent and $\mathrm{WSe}_{2}$ is only in contact with Gr. This is further visualized by a crossshaped contact scheme in Supplementary Fig. 8.

To accurately define the active area of the device, the photocurrent profile across the width of the device ( $x$ axis in Fig. 3a) is plotted on a linear scale (Fig. 3b). In this specific device, $\mathrm{MoO}_{x}$ is slightly misaligned with respect to Gr (Fig. 3a). The misalignment only occurred in few devices due to lithography issues. Most devices, such as the one shown in Fig. 1f, have wellaligned $\mathrm{Gr}$ and $\mathrm{MoO}_{x}$. On the left edge of Fig. 3b (corresponds to the upper edge in the photocurrent map), photocurrent is only generated in regions covered by Gr. The tail beyond the Gr edge occurs due to the finite laser spot size $(\sim 2 \mu \mathrm{m})$, leading to spatial averaging of the photocurrent. This spatial averaging shows up as a $\sim 2-\mu \mathrm{m}$ tail going from non-zero to zero photocurrent regimes as visible in the photocurrent profile. On the right side of Fig. 3b (corresponds to the lower edge in the photocurrent map), due to the passivation effect of $\mathrm{MoO}_{x}^{24}$, current generation goes beyond $\mathrm{Gr}$ and occurs up to the $\mathrm{MoO}_{x}$ right edge. A similar spatial averaging phenomenon is also taking place on this side, resulting in a $\sim 2-\mu \mathrm{m}$ tail beyond the $\mathrm{MoO}_{x}$ edge. The photocurrent profile confirms that photogeneration only occurs in regions covered by $\mathrm{Gr}$ (and $\mathrm{MoO}_{x}$, if misaligned) and this area can be used to accurately define the active area of the device for current density calculation, similar to other studies on vertical TMD solar cells ${ }^{22}$. The active area of the solar cells tested varies from $\sim 10^{3}$ to $\sim 10^{4} \mu \mathrm{m}^{2}$.

We measure the absorption spectrum of $\mathrm{WSe}_{2}$ solar cells at different stages of fabrication, i.e., after polyimide release $\left(\mathrm{Au}-\mathrm{WSe}_{2}\right)$, after $\mathrm{Gr}$ transfer $\left(\mathrm{Au}-\mathrm{WSe}_{2}-\mathrm{Gr}\right)$, and finally after $\mathrm{MoO}_{x}$ deposition $\left(\mathrm{Au}-\mathrm{WSe}_{2}-\mathrm{Gr}-\mathrm{MoO}_{x}\right.$ ), as shown in Fig. 3c. For consistency, each measurement is taken at exactly the same spot at the center of the active area of the device. The data in Fig. $3 \mathrm{c}$ corresponds to the device whose $J-V$ characteristics are shown in Fig. 1f. This device has a 209-nm-thick $\mathrm{WSe}_{2}$ absorber layer, as measured by a stylus-based surface profiler.

After transferring Gr on top of $\mathrm{WSe}_{2}$, the overall absorption of the stack is slightly reduced. Optical simulations using the transfer matrix method produce a similar result (Supplementary Fig. 9a). Depositing $10 \mathrm{~nm}$ of $\mathrm{MoO}_{x}$ on top of $\mathrm{Gr}$ increases the 
a

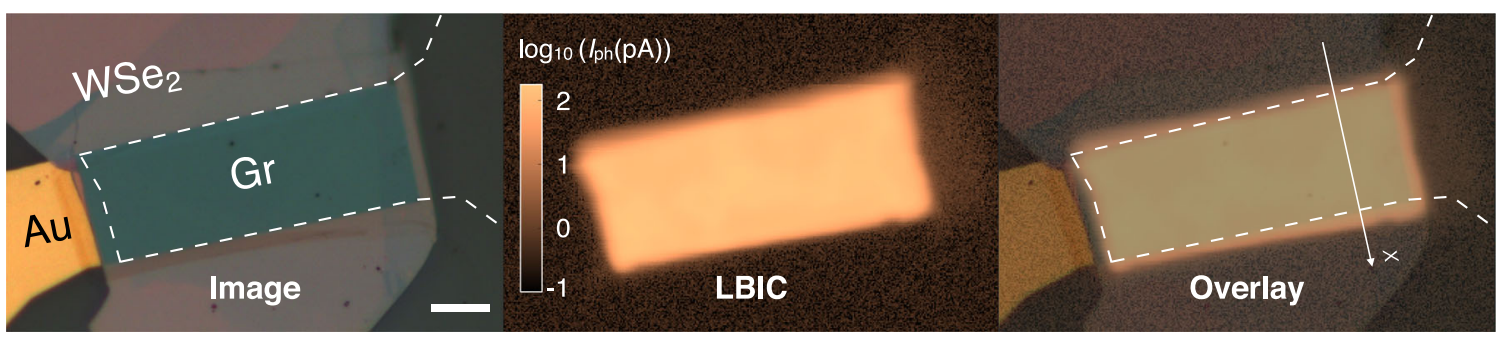

b

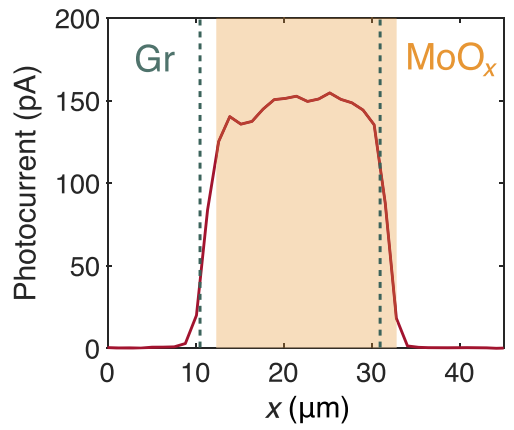

C

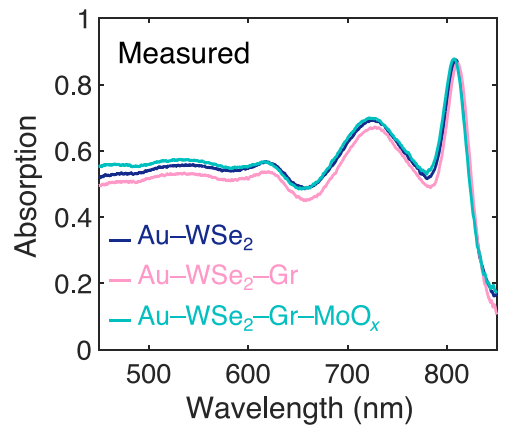

d

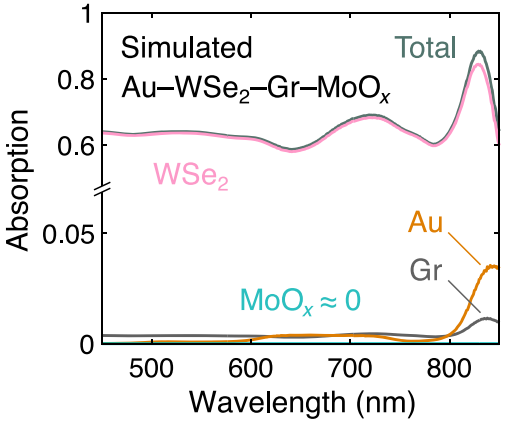

Fig. 3 Optical characteristics of flexible WSe $\mathbf{2}_{\mathbf{2}}$ solar cells. a Optical image (left), light beam-induced current (LBIC or photocurrent) map (middle), and their overlay (right) for a typical WSe $e_{2}$ solar cell, measured at $\lambda=530 \mathrm{~nm}$. Scale bar, $10 \mu \mathrm{m}$. b Photocurrent profile along the $x$ axis shown in $\mathbf{a}$, demonstrating that the $\mathrm{Gr} / \mathrm{MoO}_{x}-\mathrm{WSe} \mathrm{e}_{2}$ junction area accurately represents the active area of the solar cell. The misaligned $\mathrm{MoO}_{x}$ is passivating the $\mathrm{WSe} \mathrm{e}_{2}$ top surface ${ }^{24}$, leading to the current generation up to the edge of $\mathrm{MoO}_{x}$. The photocurrent tails beyond the edges of $\mathrm{Gr}$ and $\mathrm{MoO}_{x}$ occur due to the finite laser spot size $(\sim 2 \mu \mathrm{m})$. In most devices, $\mathrm{MoO}_{x}$ and $\mathrm{Gr}$ are fully aligned like in Fig. 1c. c Measured absorption spectra at the center of the active area, taken at various stages of the fabrication process: after polyimide release (only with $\mathrm{Au}-\mathrm{WSe}_{2}$ ), Gr transfer, and $\mathrm{MoO}_{x}$ deposition. d Simulated absorption spectra of the same device, matching well with the measurement in c. The plot also shows the contribution of each layer to the overall absorption. Nearly all absorption occurs within the 209-nm-thick $\mathrm{WS}_{2}$ absorber layer. Note the discontinuous vertical axis, used to magnify the smaller contributions.

a

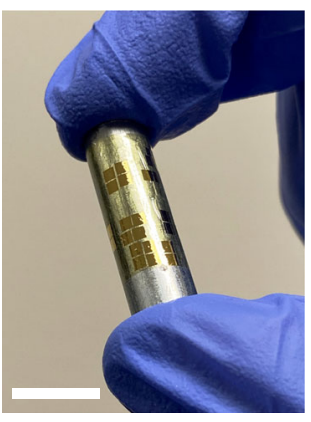

b

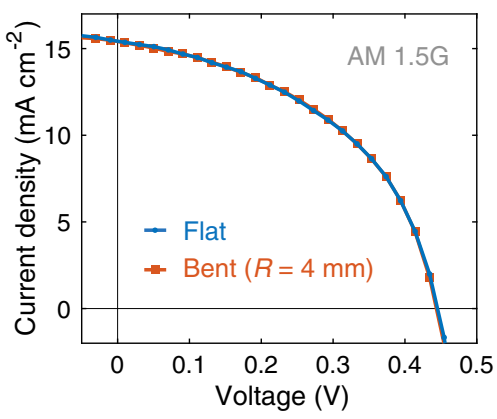

Fig. 4 Bending test. a Photograph of the bending setup. The polyimide substrate is attached to an 8 -mm-diameter metal cylinder, causing bending of the substrate at a curvature radius of $4 \mathrm{~mm}$. Scale bar, $1 \mathrm{~cm}$. b Measured $J-V$ characteristics of a typical flexible $\mathrm{WSe}_{2}$ solar cell under $\mathrm{AM} 1.5 \mathrm{G}$ illumination in flat and bent conditions. Bending does not change the $J-V$ characteristics of the device.

overall absorption of the stack. This can be either due to parasitic absorption within $\mathrm{MoO}_{x}$ or its anti-reflection coating effect improving the absorption within the $\mathrm{WSe}_{2}$ absorber layer. To answer this question, we simulate absorption using the transfer matrix method. Figure $3 \mathrm{~d}$ shows a simulated absorption spectrum of the $\mathrm{Au}-\mathrm{WS} \mathrm{S}_{2}-\mathrm{Gr}-\mathrm{MoO}_{x}$ stack along with the contribution of each individual layer. Simulated and measured absorption spectra are in good agreement, having the same shapes and magnitudes, with peaks and valleys located at similar wavelengths. The small discrepancies between the two absorption spectra can be

explained by the fact that the optical properties of $\mathrm{WSe}_{2}$ used in the simulation are taken from the literature ${ }^{62}$ and may deviate slightly from the $\mathrm{WSe}_{2}$ films in this study.

According to Fig. 3d, parasitic absorption in the $10-\mathrm{nm} \mathrm{MoO}_{x}$ layer is essentially zero. In addition, nearly all absorption occurs within the 209-nm-thick WSe ${ }_{2}$ absorber layer, indicating that the absorption boost observed after $\mathrm{MoO}_{x}$ coating (Fig. 3c) is mainly due to the increased absorption in the $\mathrm{WSe}_{2}$ layer. These observations suggest that $\mathrm{MoO}_{x}$ is acting as an anti-reflection coating for the $\mathrm{WSe}_{2}$ absorber layer. Our optical simulation confirms this hypothesis (Supplementary Fig. 9b, c), showing that adding $\mathrm{MoO}_{x}$ increases the absorption within the $\mathrm{WSe}_{2}$ layer. The simulation also reveals that an optimal choice of $\mathrm{MoO}_{x}$ thickness $(\sim 70 \mathrm{~nm})$ can lead to a significant improvement in $\mathrm{WSe}_{2}$ absorption, resulting in $J_{\mathrm{SC}}$ values up to $30 \mathrm{~mA} \mathrm{~cm}^{-2}$ (Supplementary Fig. 9c, d). This suggests that $\mathrm{MoO}_{x}$ could be used as a simple yet effective anti-reflection coating choice for TMD photovoltaics, to be further investigated in future studies.

The $\mathrm{WSe}_{2}$ solar cells show an average optical absorption of about $55 \%$ over the $450-850 \mathrm{~nm}$ wavelength spectrum. Using the simulated $\mathrm{WSe}_{2}$ absorption spectrum and assuming unity internal quantum efficiency (IQE), we calculate a maximum $J_{S C}$ of $20.0 \mathrm{~mA} \mathrm{~cm}^{-2}$, slightly underestimated because absorption at wavelengths below $400 \mathrm{~nm}$ and above $1000 \mathrm{~nm}$ are excluded due to lack of available material data (see Supplementary Fig. 9d). Given the measured $J_{\mathrm{SC}}$ of $17.3 \mathrm{~mA} \mathrm{~cm}^{-2}$ (Fig. 1f), this implies an average IQE (weighted by AM $1.5 \mathrm{G}$ spectrum) of 0.87 , which signals low levels of charge carrier recombination, in agreement with near-unity ideality factor and small dark saturation current extracted from $J-V$ measurements (Fig. 2d). Similar IQE values have been observed in other vertical Schottky junction TMD solar cells ${ }^{22}$. 
Bending test. To test the performance of devices under bending, we attach the polyimide substrate onto an 8 -mm-diameter metal cylinder, which bends the substrate at a curvature radius of $4 \mathrm{~mm}$ (Fig. 4a). The flexible $\mathrm{WSe}_{2}$ solar cells show the same $J-V$ characteristics in flat and bent states under AM $1.5 \mathrm{G}$ illumination (Fig. 4b), indicating consistent performance levels under bending. This is not surprising because given the polyimide substrate thickness of only $5 \mu \mathrm{m}$, the materials encounter small strain values of $\sim 0.06 \%$ at this bending radius ${ }^{46}$, and we expect that submillimeter bending radii should be possible given that materials involved have been shown to sustain strains of at least $0.5 \%{ }^{63-68}$. We have investigated similar TMD, metal, and dielectric stacks in electronic devices in more detail in our recent work and found that there is no discernable change of electrical device properties ${ }^{46}$. Scaling up the solar cell area will not change the device stability under strain ${ }^{63,69}$, however, we expect effects of substrate curvature on light-coupling to become relevant. For instance, it has been found that $J_{\mathrm{SC}}$ and PCE reduce ${ }^{70-72}$ by $\sim 30 \%$ under an incident angle of $45^{\circ}$. With the bending radius of $4 \mathrm{~mm}$, this would mean that a $\sim 6.3 \mathrm{~mm}$ wide solar cell would encounter such a $30 \%$ reduction at its outermost edges. Hence, for our solar cells with small, exfoliated flakes on length scales that are tens of microns, there is no effect of substrate curvature on the lightcoupling, as seen in Fig. $4 \mathrm{~b}$. In the future, if the active area of the solar cell is increased, e.g., by large-area synthesis of TMDs, these bending studies will become more important to quantify the effects of the bent surface on light-coupling and thus $J_{S C}$, which would alter solar cell performance.

Benchmarking and projections. Figure 5 benchmarks the PCE and $P_{\mathrm{S}}$ of the flexible WSe $\mathrm{W}_{2}$ solar cells in this work against other thin-film solar technologies (details in Supplementary Note 4). The flexible $\mathrm{WSe}_{2}$ solar cells in this study demonstrate remarkable improvements of about $10 \times$ and $100 \times$ in PCE and $P_{\mathrm{S}}$,

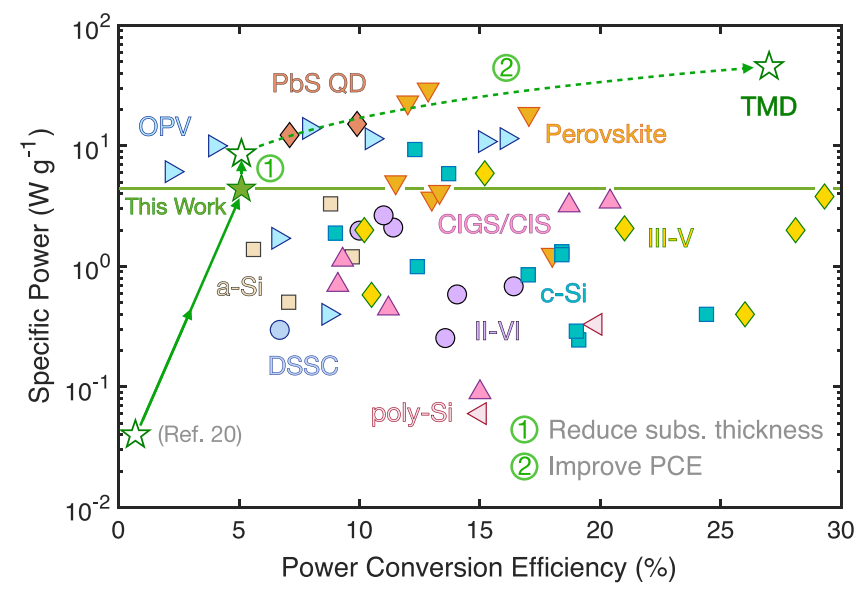

Fig. 5 Power conversion efficiency (PCE) and specific power (power per weight) of lightweight and flexible thin-film solar technologies. Our

flexible TMD $\left(\mathrm{WSe}_{2}\right)$ solar cell achieves a relatively high specific power despite its moderate PCE (filled green star). Arrow 1 shows the projected effect of reducing substrate thickness, arrow 2 shows the projected effect of improving PCE. With these improvements, TMD solar cells could reach unprecedented specific power in the future. More details are given in Supplementary Note 4. OPV organic photovoltaics, PbS QD lead sulfide quantum dot, CIGS/CIS copper indium (gallium) selenide, c-Si crystalline silicon, a-Si amorphous silicon, poly-Si polycrystalline silicon, DSSC dyesensitized solar cell, III-V (II-VI) compound semiconductors containing elements from groups three and five (or two and six) in the periodic table (see Supplementary Table 3 for more details and references). respectively, compared to the previous results in flexible TMD solar cells $\left(\mathrm{PCE}<0.7 \% \text { and } P_{\mathrm{S}}<0.04 \mathrm{~W} \mathrm{~g}^{-1}\right)^{20}$. With only a moderate PCE of $5.1 \%$, the $\mathrm{WSe}_{2}$ solar cells already achieve a high-specific power of $4.4 \mathrm{~W} \mathrm{~g} \mathrm{~g}^{-1}$ enabled by their ultrathin $\mathrm{WSe}_{2}$ absorber layer and lightweight polyimide substrate. This high $P_{\mathrm{S}}$ is in the same range as champion solar cells of well-established thin-film technologies CdTe (II-VI), CIGS, a-Si, and III-Vs ${ }^{38-45}$.

By reducing the polyimide substrate thickness to $1 \mu \mathrm{m}$, same as in some of the champion organic PV (OPV) and perovskite solar cells in Fig. 5, specific power can be further increased to $8.6 \mathrm{~W} \mathrm{~g}^{-1}$ (path \#1 in Fig. 5). According to realistic detailed balance models developed for TMD photovoltaic cells, single-junction multilayer TMDs can in principle achieve $22 \%$ PCE with an optimized optical and electronic design ${ }^{13}$. We have estimated similar values specifically for $\mathrm{WSe}_{2}$ solar cells as shown in Supplementary Note 5 and Supplementary Fig. 10. Such PCE would lead to an ultrahigh specific power of $46 \mathrm{~W} \mathrm{~g}^{-1}$ (path \#2 in Fig. 5), by far outperforming all other thin-film technologies, including perovskite solar cells which currently hold the record for specific power $\left(29.4 \mathrm{~W} \mathrm{~g}^{-1}\right)^{73}$. In addition, TMD solar cells do not have the stability challenges of OPV or perovskites, and in contrast to highperforming perovskites and lead sulfide ( $\mathrm{PbS}$ ) quantum dots, they do not contain toxic elements such as lead, and therefore are not expected to pose any significant environmental or health hazards ${ }^{74}$.

Future research. In order to achieve the projected $27 \%$ PCE in the flexible $\mathrm{WSe}_{2}$ solar cells, both optical and electronic designs need to be improved. As pointed out earlier, $\mathrm{MoO}_{x}$ can serve as an effective anti-reflection coating for $\mathrm{WSe}_{2}$. Our optical simulation shows that simply increasing the thickness of $\mathrm{MoO}_{x}$ to an optimal value of $\sim 70 \mathrm{~nm}$ is supposed to improve the absorption within the $\mathrm{WSe}_{2}$ layer to $80 \%$ and enable $J_{\mathrm{SC}}$ values up to $30 \mathrm{~mA} \mathrm{~cm}^{-2}$ (Supplementary Fig. 9c, d). Metasurface-based plasmonic light-trapping schemes can help further improve absorption and reach $J_{\mathrm{SC}}$ values near the Shockley-Queisser limit $\left(40 \mathrm{~mA} \mathrm{~cm}^{-2} \text { for a bandgap of } 1.2 \mathrm{eV}\right)^{75-79}$.

$V_{\mathrm{OC}}$ is another important area of improvement. The built-in potential and therefore $V_{\mathrm{OC}}$ of these devices can be improved by employing n-type $\mathrm{WSe}_{2}$. The doping process can be performed during growth, or by means of ultrathin metal-oxide interlayers such as $\mathrm{AlO}_{x}$ and $\mathrm{TiO}_{x}$ placed between the TMD absorber layer and the metallic bottom contact ${ }^{80,81}$. Replacing $\mathrm{Au}$ with a lower work function metal but ensuring a similar interface quality could also improve $V_{\text {OC. }}$. We showed in our experiments that $\mathrm{Al}$ and $\mathrm{Ti}$ are not good candidates for this purpose (Supplementary Fig. 2). Forming a high built-in potential p-n heterojunction (e.g., $\mathrm{WSe}_{2} /$ $\mathrm{MoS}_{2}$ ) or homojunction, possibly by metal-oxide-based p-type $\left(\mathrm{MoO}_{x}\right)$ and n-type $\left(\mathrm{AlO}_{x}\right)$ doping, is another way to achieve a high $V_{\mathrm{OC}}{ }^{23-25,80,82,83}$. One can also improve the $V_{\mathrm{OC}}$ by adopting carrier-selective (MIS) contacts which both de-pin the Fermi level and enable a selective collection of only one type of charge carrier on each side of the solar cell ${ }^{28-31,84,85}$.

Research efforts to scale up TMD growth to large areas would soon enable scalable and low-cost production of TMD photovoltaic cells ${ }^{86,87}$, similar to other chalcogenide solar cells CdTe and CIGS. The potential of TMDs to achieve high power conversion efficiency and specific power at a low cost as well as their stability and environmentally friendliness (in contrast to perovskites) makes them a serious candidate for next-generation photovoltaics, especially in high-specific-power applications.

In summary, we demonstrated flexible $\mathrm{WSe}_{2}$ solar cells with record-breaking power conversion efficiency PCE of $5.1 \%$ and power per weight $P_{\mathrm{S}}$ of $4.4 \mathrm{~W} \mathrm{~g}^{-1}$. We performed detailed optical and electrical characterizations on these solar cells to explain their 
superior performance and identify areas of improvement, providing practical guidelines on the optical and electronic design to enhance PCE and $P_{\mathrm{S}}$. We also tested the flexible solar cells under bending and showed similar performance in flat and bent states. Future large-area TMD cells will require more bending studies to verify the effects of light-coupling at different angles on solar cell performance. Lastly, we benchmarked the flexible $\mathrm{WSe}_{2}$ solar cells against other thin-film photovoltaic technologies and showed their potential to achieve ultrahigh $P_{\mathrm{S}}$, creating unprecedented opportunities in a broad range of industries from aerospace to wearable electronics.

\section{Methods}

Device fabrication. The details on device fabrication are provided in Supplementary Note 1 . In short, $\mathrm{WSe}_{2}$ flakes were mechanically exfoliated onto $\mathrm{Si} / \mathrm{SiO}_{2}$ substrates. Next, $135 \mathrm{~nm}$ of Au serving as solar cell bottom contacts was electronbeam evaporated and structured by optical photolithography and lift-off. Then the flexible polyimide substrate was spin-coated on top, cured and all structures were released together in deionized water. After flipping the substrate, graphene was wet-transferred as transparent top contact and structured by optical photolithography and dry etching. Finally, $\mathrm{MoO}_{x}$ was deposited by electron-beam evaporation and structured by optical photolithography and lift-off, followed by annealing in ambient air for the purpose of doping, passivation, and anti-reflection coating. The process flow is schematically shown in Supplementary Fig. 1. The thickness of WSe ${ }_{2}$ flakes was measured by atomic force microscopy (AFM, Bruker Dimension Icon) and/or stylus-based surface profilometry (Alphastep 500) after exfoliation on the $\mathrm{Si} / \mathrm{SiO}_{2}$ substrate.

AM 1.5 G current-voltage measurements. AM $1.5 \mathrm{G} I-V$ measurements were done using a digital source meter (Keithley 2420) and a class AAA solar simulator (Newport, Oriel Sol3A Class AAA) having a $450 \mathrm{~W}$ xenon short arc lamp and AM $1.5 \mathrm{G}$ spectral correction filter. Lamp intensity calibration was done using a silicon reference cell (Newport, Oriel $91150 \mathrm{~V}$ ) placed at the location of the sample. The silicon reference cell was calibrated by Newport Corporation. $I-V$ characteristics were measured with a scan rate of $200 \mathrm{mV} \mathrm{s}^{-1}$ and a dwell time of $30 \mathrm{~ms}$. The measurements were performed in air. The samples were kept at room temperature via convection cooling provided by a fan. In all $I-V$ measurements, the voltage was applied to the graphene top contact, while the gold bottom contact was grounded.

Photocurrent mapping. The photocurrent from the device was measured on a custom-built optoelectronic setup. A supercontinuum laser source (Fianium) and an acousto-optic tunable filter (Fianium) were used to provide monochromatic illumination across a broad spectral range. To achieve a high signal-to-noise ratio, the laser light was modulated by a chopper wheel $(400 \mathrm{~Hz})$ synchronized with two lock-in amplifiers. The laser light was focused onto the sample using a 50X long working distance objective (Mitutoyo M Plan APO NIR). To image the sample, two beam splitters were placed in the illumination path for a halogen lamp and a charge-coupled device (CCD) imaging camera, respectively. Using a glass slide, a small fraction of the reflected light was directed into a large-area Si photodiode (New Focus, model 2031) connected to a lock-in amplifier (Stanford Research SR810 DSP) to measure reflection from the sample. The sample was placed on a chip carrier and then mounted on a three-axis piezo stage to accurately control its spatial position. Electrical connections were made by soldering wires (34-gauge enameled wires) using thermally stable solder paste Sn42/Bi57.6/Ag0.4 T4 (Chip Quik) onto the Au metal pads. To measure the photocurrent, the mounted sample was connected in series with a source meter (Keithley 2612), a tunable current-tovoltage amplifier, and a second lock-in amplifier (Stanford Research SR810 DSP).

\begin{abstract}
Absorption measurement. The absorption measurements were performed using a Nikon C2 confocal microscope coupled to a CCD camera (Acton Pixis 1024, Princeton Instrument) and a spectrometer (Acton SP2300i, Princeton Instrument). Unpolarized light from a halogen lamp was used to illuminate the sample through a $20 \mathrm{X}$ objective (Nikon CFI Achromat LWD, NA = 0.4). The reflection spectra $(R(\lambda))$ were normalized to the calibrated reflection spectrum of a protected silver mirror (Thorlabs, PF10-03-P01). Since all devices were fabricated on top of thick Au contact, the absorption spectra $(A(\lambda))$ were calculated by $A(\lambda)=1-R(\lambda)$.
\end{abstract}

Raman spectroscopy. The Raman measurements were performed on a HORIBA Scientific LabRAM HR Evolution spectrometer using an excitation wavelength of $532 \mathrm{~nm}$. For Raman measurements, an acquisition time, accumulations, laser power, and the optical grating of $20 \mathrm{~s}, 2,2.8 \mathrm{~mW}, 1800 \mathrm{gr} \mathrm{mm}^{-1}$ were used, and the spot size is $<1 \mu \mathrm{m}$.

Optical simulation. Optical simulations were performed using the transfer matrix method. A normally incident plane wave was assumed in all simulations. The thickness of each layer used in simulations is shown in Fig. 1b. The bottom Au contact was modeled as a semi-infinite substrate due to its small penetration depth Optical constants for $\mathrm{WSe}_{2}, \mathrm{Gr}$, and Au were taken from the literature ${ }^{62,88,89}$. Optical constants for $\mathrm{MoO}_{x}$ were obtained experimentally from spectroscopic ellipsometry $(n \approx 2.0)$.

Reporting summary. Further information on research design is available in the Nature Research Reporting Summary linked to this article.

\section{Data availability}

The data that support the findings of this study are available from the corresponding author upon reasonable request.

Received: 6 July 2021; Accepted: 1 November 2021; Published online: 09 December 2021

\section{References}

1. Philipps, S. et al. Photovoltaics Report (Fraunhofer Institute for Solar Energy Systems, 2020).

2. Jeong, S., McGehee, M. D. \& Cui, Y. All-back-contact ultra-thin silicon nanocone solar cells with $13.7 \%$ power conversion efficiency. Nat. Commun. 4 2950 (2013).

3. Lee, S.-M. et al. Printable nanostructured silicon solar cells for high-performance, large-area flexible photovoltaics. ACS Nano 8, 10507-10516 (2014).

4. Lin, Q. et al. High performance thin film solar cells on plastic substrates with nanostructure-enhanced flexibility. Nano Energy 22, 539-547 (2016).

5. Sun, X. et al. Firmly standing three-dimensional radial junctions on soft aluminum foils enable extremely low cost flexible thin film solar cells with very high power-to-weight performance. Nano Energy 53, 83-90 (2018).

6. Das, S. et al. A leaf-inspired photon management scheme using optically tuned bilayer nanoparticles for ultra-thin and highly efficient photovoltaic devices. Nano Energy 58, 47-56 (2019).

7. Xue, M. et al. Free-standing $2.7 \mu \mathrm{m}$ thick ultrathin crystalline silicon solar cell with efficiency above 12.0\%. Nano Energy 70, 104466 (2020).

8. Kaltenbrunner, M. et al. Flexible high power-per-weight perovskite solar cells with chromium oxide-metal contacts for improved stability in air. Nat. Mater. 14, 1032-1039 (2015).

9. Reese, M. O. et al. Increasing markets and decreasing package weight for highspecific-power photovoltaics. Nat. Energy 3, 1002-1012 (2018).

10. Song, Y., Min, J. \& Gao, W. Wearable and implantable electronics: moving toward precision therapy. ACS Nano 13, 12280-12286 (2019).

11. Mak, K. F., Lee, C., Hone, J., Shan, J. \& Heinz, T. F. Atomically thin $\operatorname{MoS}_{2}$ : a new direct-gap semiconductor. Phys. Rev. Lett. 105, 2-5 (2010).

12. Splendiani, A. et al. Emerging photoluminescence in monolayer $\mathrm{MoS}_{2}$. Nano Lett. 10, 1271-1275 (2010).

13. Jariwala, D., Davoyan, A. R., Wong, J. \& Atwater, H. A. Van der Waals materials for atomically-thin photovoltaics: promise and outlook. ACS Photonics 4, 2962-2970 (2017).

14. Bernardi, M., Palummo, M. \& Grossman, J. C. Extraordinary sunlight absorption and one nanometer thick photovoltaics using two-dimensional monolayer materials. Nano Lett. 13, 3664-3670 (2013).

15. Jariwala, D. et al. Near-unity absorption in van der Waals semiconductors for ultrathin optoelectronics. Nano Lett. 16, 5482-5487 (2016).

16. Huang, L. et al. Atomically thin $\mathrm{MoS}_{2}$ narrowband and broadband light superabsorbers. ACS Nano 10, 7493-7499 (2016).

17. Wang, L. et al. 2D photovoltaic devices: progress and prospects. Small Methods 1700294, 1700294 (2018).

18. Wang, H. et al. Two-dimensional heterostructures: fabrication, characterization, and application. Nanoscale 6, 12250-12272 (2014).

19. Li, H.-M. et al. Ultimate thin vertical p-n junction composed of twodimensional layered molybdenum disulfide. Nat. Commun. 6, 6564 (2015)

20. Akama, T. et al. Schottky solar cell using few-layered transition metal dichalcogenides toward large-scale fabrication of semitransparent and flexible power generator. Sci. Rep. 7, 11967 (2017)

21. Mao, X., Zou, J., Li, H., Song, Z. \& He, S. Magnetron sputtering fabrication and photoelectric properties of $\mathrm{WSe}_{2}$ film solar cell device. Appl. Surf. Sci. 444, 126-132 (2018).

22. Went, C. M. et al. A new metal transfer process for van der Waals contacts to vertical Schottky-junction transition metal dichalcogenide photovoltaics. Sci. $A d v$. 5, eaax6061 (2019)

23. McVay, E., Zubair, A., Lin, Y., Nourbakhsh, A. \& Palacios, T. Impact of $\mathrm{Al}_{2} \mathrm{O}_{3}$ passivation on the photovoltaic performance of vertical WSe $\mathrm{S}_{2}$ Schottky junction solar cells. ACS Appl. Mater. Interfaces 12, 57987-57995 (2020).

24. Nassiri Nazif, K. et al. High-performance $\mathrm{p}-\mathrm{n}$ junction transition metal dichalcogenide photovoltaic cells enabled by $\mathrm{MoO}_{\mathrm{x}}$ doping and passivation. Nano Lett. 21, 3443-3450 (2021). 
25. Nassiri Nazif, K., Kumar, A., Moreira De Menezes, M. T. \& Saraswat, K. Towards high $\mathrm{V}_{\mathrm{oc}}$, thin film, homojunction $\mathrm{WS}_{2}$ solar cells for energy harvesting applications. Proc. SPIE, Wide Bandgap Materials, Devices, and Applications IV 11126, 7 (2019).

26. Liu, Y. et al. Approaching the Schottky-Mott limit in van der Waals metal-semiconductor junctions. Nature 557, 696-700 (2018).

27. Zhao, Y. et al. Doping, contact and interface engineering of two-dimensional layered transition metal dichalcogenides transistors. Adv. Funct. Mater. 27, 1603484 (2017).

28. Chen, J.-R. et al. Control of Schottky barriers in single layer $\mathrm{MoS}_{2}$ transistors with ferromagnetic contacts. Nano Lett. 13, 3106-3110 (2013).

29. Lee, S., Tang, A., Aloni, S. \& Wong, H.-S.P. Statistical study on the Schottky barrier reduction of tunneling contacts to CVD synthesized $\mathrm{MoS}_{2}$. Nano Lett. 16, 276-281 (2015).

30. Mleczko, M.J. et al. Contact Engineering High-Performance n-Type $\mathrm{MoTe}_{2}$ Transistors. Nano Lett. 19, 6352-6362 (2019).

31. Lim, J. et al. Contact engineering of vertically grown $\mathrm{ReS}_{2}$ with Schottky barrier modulation. ACS Appl. Mater. Interfaces 13, 7529-7538 (2021)

32. Le Quang, T. et al. Scanning tunneling spectroscopy of van der Waals graphene/semiconductor interfaces: absence of Fermi level pinning. 2D Mater. 4, 35019 (2017).

33. LaGasse, S. W., Dhakras, P., Watanabe, K., Taniguchi, T. \& Lee, J. U. Gatetunable graphene-WSe $e_{2}$ heterojunctions at the Schottky-Mott limit. Adv. Mater. 31, 1901392 (2019).

34. Yeh, C.-H. et al. Graphene-transition metal dichalcogenide heterojunctions for scalable and low-power complementary integrated circuits. ACS Nano 14, 985-992 (2020).

35. Wi, S. et al. Enhancement of photovoltaic response in multilayer $\mathrm{MoS}_{2}$ induced by plasma doping. ACS Nano 8, 5270-5281 (2014).

36. Memaran, S. et al. Pronounced photovoltaic response from multilayered transition-metal dichalcogenides PN-junctions. Nano Lett. 15, 7532-7538 (2015).

37. Shinde, S. M. et al. Surface-functionalization-mediated direct transfer of molybdenum disulfide for large-area flexible devices. Adv. Funct. Mater. 28, 1706231 (2018).

38. Romeo, A., Arnold, M., Bätzner, D. L., Zogg, H. \& Tiwari, A. N. Development of high efficiency flexible solar cells. PV Eur. PV Technol. Energy Solut. 1, 377-381 (2002).

39. Romeo, A. et al. High-efficiency flexible CdTe solar cells on polymer substrates. Sol. Energy Mater. Sol. Cells 90, 3407-3415 (2006).

40. Chirilă, A. et al. Highly efficient $\mathrm{Cu}(\mathrm{In}, \mathrm{Ga}) \mathrm{Se}_{2}$ solar cells grown on flexible polymer films. Nat. Mater. 10, 857-861 (2011).

41. Chirilă, A. et al. Potassium-induced surface modification of $\mathrm{Cu}(\mathrm{In}, \mathrm{Ga})$ $\mathrm{Se}_{2}$ thin films for high-efficiency solar cells. Nat. Mater. 12, 1107-1111 (2013).

42. Söderström, T., Haug, F.-J., Terrazzoni-Daudrix, V. \& Ballif, C. Optimization of amorphous silicon thin film solar cells for flexible photovoltaics. J. Appl. Phys. 103, 114509 (2008).

43. $\mathrm{Xu}, \mathrm{X}$. et al. High efficiency ultra lightweight a-Si:H/a-SiGe:H/a-SiGe:H triplejunction solar cells on polymer substrate using roll-to-roll technology. In 2008 33rd IEEE Photovoltaic Specialists Conference 1-6 (2008).

44. Kim, J. et al. Ultra-thin flexible GaAs photovoltaics in vertical forms printed on metal surfaces without interlayer adhesives. Appl. Phys. Lett. 108, 253101 (2016).

45. Cardwell, D. et al. Very high specific power ELO solar cells $(>3 \mathrm{~kW} / \mathrm{kg}$ ) for UAV, space, and portable power applications. In 2017 IEEE 44th Photovoltaic Specialist Conference (PVSC) 3511-3513 (2017).

46. Daus, A. et al. High-performance flexible nanoscale transistors based on transition metal dichalcogenides. Nat. Electron. 4, 495-501 (2021).

47. Kam, K. K. \& Parkinson, B. A. Detailed photocurrent spectroscopy of the semiconducting group VIB transition metal dichalcogenides. J. Phys. Chem. 86, 463-467 (1982).

48. Traving, $\mathrm{M}$. et al. Electronic structure of $\mathrm{WSe}_{2}$ : a combined photoemission and inverse photoemission study. Phys. Rev. B 55 10392-10399 (1997).

49. Schlaf, R., Lang, O., Pettenkofer, C. \& Jaegermann, W. Band lineup of layered semiconductor heterointerfaces prepared by van der Waals epitaxy: charge transfer correction term for the electron affinity rule. J. Appl. Phys. 85, 2732-2753 (1999).

50. Das, S. \& Appenzeller, J. WSe $e_{2}$ field effect transistors with enhanced ambipolar characteristics. Appl. Phys. Lett. 103, 103501 (2013).

51. Lee, I. et al. Non-degenerate n-type doping by hydrazine treatment in metal work function engineered WSe ${ }_{2}$ field-effect transistor. Nanotechnology 26, 455203 (2015).

52. Schauble, $\mathrm{K}$. et al. Uncovering the effects of metal contacts on monolayer $\mathrm{MoS}_{2}$. ACS Nano 14, 14798-14808 (2020).

53. Vaziri, S. et al. Ultrahigh doping of graphene using flame-deposited $\mathrm{MoO}_{3}$. IEEE Electron Device Lett. 41, 1592-1595 (2020).
54. Yan, R. et al. Determination of graphene work function and grapheneinsulator-semiconductor band alignment by internal photoemission spectroscopy. Appl. Phys. Lett. 101, 22105 (2012).

55. Song, S. M., Park, J. K., Sul, O. J. \& Cho, B. J. Determination of work function of graphene under a metal electrode and its role in contact resistance. Nano Lett. 12, 3887-3892 (2012).

56. Avsar, A. et al. Reconfigurable diodes based on vertical WSe $\mathrm{W}_{2}$ transistors with van der Waals bonded contacts. Adv. Mater. 30, 1707200 (2018).

57. Demtsu, S. H. \& Sites, J. R. Effect of back-contact barrier on thin-film CdTe solar cells. Thin Solid Films 510, 320-324 (2006).

58. Niemegeers, A. \& Burgelman, M. Effects of the Au/CdTe back contact on IV and CV characteristics of Au/CdTe/CdS/TCO solar cells. J. Appl. Phys. 81, 2881-2886 (1997).

59. Kato, T. et al. Characterization of the back contact of CIGS solar cell as the origin of rollover effect. In 32nd European Photovoltaic Solar Energy Conference and Exhibition 1085-1088 (2016).

60. Waldauf, C., Scharber, M. C., Schilinsky, P., Hauch, J. A. \& Brabec, C. J. Physics of organic bulk heterojunction devices for photovoltaic applications. J. Appl. Phys. 99, 104503 (2006)

61. Würfel, U., Cuevas, A. \& Würfel, P. Charge carrier separation in solar cells. IEEE J. Photovolt. 5, 461-469 (2015).

62. Rubio-Bollinger, G. et al. Enhanced visibility of $\mathrm{MoS}_{2}, \mathrm{MoSe}_{2}, \mathrm{WSe}_{2}$ and black-phosphorus: making optical identification of 2D semiconductors easier. Electronics 4, 847-856 (2015).

63. Senthil Kumar, K., Chen, P.-Y. \& Ren, H. A review of printable flexible and stretchable tactile sensors. Research 2019, 3018568 (2019).

64. Münzenrieder, N. et al. Investigation of gate material ductility enables flexible a-IGZO TFTs bendable to a radius of $1.7 \mathrm{~mm}$. In 2013 Proceedings of the European Solid-State Device Research Conference (ESSDERC) 362-365 (2013).

65. Wang, F. et al. Strain engineering in monolayer $\mathrm{WS}_{2}$ and $\mathrm{WS}_{2}$ nanocomposites. 2D Mater. 7, 45022 (2020).

66. Zhang, R., Koutsos, V. \& Cheung, R. Elastic properties of suspended multilayer $\mathrm{WSe}_{2}$. Appl. Phys. Lett. 108, 42104 (2016).

67. Abachi, T. et al. Highly flexible, conductive and transparent $\mathrm{MoO}_{3} / \mathrm{Ag} / \mathrm{MoO}_{3}$ multilayer electrode for organic photovoltaic cells. Thin Solid Films 545, 438-444 (2013).

68. Lucarelli, G. \& Brown, T. M. Development of highly bendable transparent window electrodes based on $\mathrm{MoO}_{\mathrm{x}}, \mathrm{SnO}_{2}$, and $\mathrm{Au}$ dielectric/metal/dielectric stacks: application to indium tin oxide (ITO)-free perovskite solar cells. Front. Mater. 6, 310 (2019).

69. Lewis, J. Material challenge for flexible organic devices. Mater. Today $\mathbf{9}, \mathbf{3 8}-45$ (2006).

70. Roy, A. B. et al. Black silicon solar cell: analysis optimization and evolution towards a thinner and flexible future. Nanotechnology 27, 305302 (2016).

71. Roy, A. B., Das, S., Kundu, A., Banerjee, C. \& Mukherjee, N. c-Si/n-ZnO-based flexible solar cells with silica nanoparticles as a light trapping metamaterial. Phys. Chem. Chem. Phys. 19, 12838-12844 (2017).

72. Kim, B. J. et al. Highly efficient and bending durable perovskite solar cells: toward a wearable power source. Energy Environ. Sci. 8, 916-921 (2015)

73. Kang, S. et al. Ultrathin, lightweight and flexible perovskite solar cells with an excellent power-per-weight performance. J. Mater. Chem. A 7, 1107-1114 (2019).

74. Fojtů, M., Teo, W. Z. \& Pumera, M. Environmental impact and potential health risks of 2D nanomaterials. Environ. Sci. Nano 4, 1617-1633 (2017).

75. Kim, S. J., Fan, P., Kang, J.-H. \& Brongersma, M. L. Creating semiconductor metafilms with designer absorption spectra. Nat. Commun. 6, 7591 (2015).

76. Park, J., Kang, J., Kim, S. J., Hasman, E. \& Brongersma, M. L. Tuning optical absorption in an ultrathin lossy film by use of a metallic metamaterial mirror. IEEE Photonics Technol. Lett. 27, 1617-1620 (2015).

77. Park, J., Kim, S. J. \& Brongersma, M. L. Condition for unity absorption in an ultrathin and highly lossy film in a Gires-Tournois interferometer configuration. Opt. Lett. 40, 1960-1963 (2015).

78. Park, J. et al. Omnidirectional near-unity absorption in an ultrathin planar semiconductor layer on a metal substrate. ACS Photonics 1, 812-821 (2014).

79. Rühle, S. Tabulated values of the Shockley-Queisser limit for single junction solar cells. Sol. Energy 130, 139-147 (2016).

80. McClellan, C. J., Yalon, E., Smithe, K. K. H., Suryavanshi, S. V. \& Pop, E. High current density in monolayer $\mathrm{MoS}_{2}$ doped by $\mathrm{AlO}_{x}$. ACS Nano 15, 1587-1596 (2021).

81. Rai, A. et al. Air stable doping and intrinsic mobility enhancement in monolayer molybdenum disulfide by amorphous titanium suboxide encapsulation. Nano Lett. 15, 4329-4336 (2015).

82. Cai, L. et al. Rapid flame synthesis of atomically thin $\mathrm{MoO}_{3}$ down to monolayer thickness for effective hole doping of $\mathrm{WSe}_{2}$. Nano Lett. 17, 3854-3861 (2017).

83. Kumar, A., Nassiri Nazif, K., Ramesh, P. \& Saraswat, K. Doped WS transistors with large on-off ratio and high on-current. In 2020 Device Research Conference (DRC) 1-2 (2020). 
84. Islam, R., Nassiri Nazif, K. \& Saraswat, K. C. Si heterojunction solar cells: a simulation study of the design issues. IEEE Trans. Electron Devices $\mathbf{6 3}$, 4788-4795 (2016).

85. Islam, R., Nassiri Nazif, K. \& Saraswat, K. Optimization of selective contacts in Si heterojunction photovoltaic cells considering Fermi level pinning and interface passivation. In IEEE Photovoltaic Specialists Conference 1-4 (2016).

86. Xiong, L. et al. Research progress on the preparations, characterizations and applications of large scale 2D transition metal dichalcogenides films. FlatChem 21, 100161 (2020).

87. Wang, M. et al. Manufacturing strategies for wafer-scale two-dimensional transition metal dichalcogenide heterolayers. J. Mater. Res. 35, 1350-1368 (2020).

88. Bruna, M. \& Borini, S. Optical constants of graphene layers in the visible range. Appl. Phys. Lett. 94, 31901 (2009).

89. Palik, E. D. Handbook of Optical Constants of Solids (Academic Press, Cambridge, 1998).

\section{Acknowledgements}

Part of this work was performed at the Stanford Nanofabrication Facility (SNF) and Stanford Nano Shared Facilities (SNSF), supported by the National Science Foundation under award ECCS-2026822. We would like to thank SNF staff members for their help with the fabrication process. A.D. was supported by the Swiss National Science Foundation's Early Postdoc.Mobility fellowship (grant P2EZP2_181619), the Beijing Institute of Collaborative Innovation (BICI), and by the National Science Foundation (NSF) Engineering Research Center for Power Optimization of Electro-Thermal Systems (POETS) with Cooperative Agreement No. EEC-1449548. N.L., J.H., and M.L.B. acknowledge support from the Department of Energy Grant DE-FG07- ER46426. We acknowledge partial support from the member companies of the SystemX Alliance at Stanford.

\section{Author contributions}

K.N. and A.D. contributed equally. K.N., A.D., and S.V. conceived the project. K.N. and A.D. fabricated the devices, assisted by S.V., A.K., and M.E.C. J.H. carried out the photocurrent measurements, assisted by S.K. for electrical connections made via soldering. N.L. did the absorption measurements, assisted by J.H. K.N., A.D., and A.K. performed the $J-V$, Raman/ellipsometry, and AFM measurements, respectively. A.D. and K.N. did the surface profilometry measurements and mechanical bending tests. N.L. and
J.H. carried out the optical simulations. F.N. and K.N. performed data analysis on $J-V$ measurements. All authors, i.e., K.N., A.D., J.H., N.L, S.V., A.K., F.N., M.E.C., S.K., R.I., K.-H.K., J.-H.P., A.S.Y.P., M.L.B., E.P., and K.C.S contributed to the data interpretation, presentation, and writing of the manuscript. K.C.S. supervised the work.

\section{Competing interests}

The authors declare no competing interests.

\section{Additional information}

Supplementary information The online version contains supplementary material available at https://doi.org/10.1038/s41467-021-27195-7.

Correspondence and requests for materials should be addressed to Krishna C. Saraswat.

Peer review information Nature Communications thanks Kian Loh and the other, anonymous, reviewer(s) for their contribution to the peer review of this work.

Reprints and permission information is available at http://www.nature.com/reprints

Publisher's note Springer Nature remains neutral with regard to jurisdictional claims in published maps and institutional affiliations.

(c) Open Access This article is licensed under a Creative Commons Attribution 4.0 International License, which permits use, sharing, adaptation, distribution and reproduction in any medium or format, as long as you give appropriate credit to the original author(s) and the source, provide a link to the Creative Commons license, and indicate if changes were made. The images or other third party material in this article are included in the article's Creative Commons license, unless indicated otherwise in a credit line to the material. If material is not included in the article's Creative Commons license and your intended use is not permitted by statutory regulation or exceeds the permitted use, you will need to obtain permission directly from the copyright holder. To view a copy of this license, visit http://creativecommons.org/ licenses/by/4.0/.

(C) The Author(s) 2021 